\title{
Availability of extended-release naltrexone may increase the number of opioid- dependent individuals in treatment. Extension of a randomized clinical trial
}

Kristin Klemmetsby Solli ${ }^{1,2,3}$, Nikolaj Kunoe ${ }^{1}$, Zill-e-Huma Latif ${ }^{2}$, Kamni Sharma-Haase $^{3}$, Arild Opheim $^{4,5}$, Peter Krajci ${ }^{6}$, Zhanna Gaulen ${ }^{4,5}$, Jūratė Šaltytė Benth ${ }^{7,8}$, Lars Tanum²,9

\footnotetext{
${ }^{1}$ Norwegian Centre for Addiction Research, University of Oslo, 0315 Oslo, Norway

${ }^{2}$ Akershus University Hospital, Dept. of R\&D in Mental Health, 1478 Loerenskog, Norway

${ }^{3}$ Vestfold Hospital Trust, 3116 Toensberg, Norway

${ }^{4}$ Haukeland University Hospital, Dept. of Addiction Medicine, 5020 Bergen, Norway

5 The University of Bergen, 5020 Bergen, Norway

${ }^{6}$ Oslo University Hospital, Dept. of Addiction Medicine, 0450 Oslo, Norway

${ }^{7}$ Institute of Clinical Medicine, Campus Ahus, University of Oslo, 0318 Blindern, Norway

${ }^{8}$ Health Services Research Unit, Akershus University Hospital, 1478 Loerenskog, Norway

${ }^{9}$ Oslo Metropolitan University, 0167 Oslo, Norway
}

Corresponding author: Kristin Klemmetsby Solli,

e-mail: k.k.solli@medisin.uio.no

Phone: +4747905895

Running head: Extended-release naltrexone

\section{Acknowledgements}

This work was supported by unrestricted grants from the Research Council of Norway (Grant \# 204725-3) and the Western Norway Regional Health Authority. Financial support was also received from the Norwegian Centre for Addiction Research, University of Oslo, and from Akershus University Hospital. Extended-release naltrexone (Vivitrol®) was provided to this investigator-initiated study by the manufacturer Alkermes. Inc.

The authors wish to thank all the participants who shared their stories with us. We also thank the study sites and staff members that helped recruit participants.

Declaration of interests: The sponsors and the manufacturer did not possess any editorial control or access to study data. The authors have no conflicts of interest to declare. 
Keywords: Naltrexone, extended-release naltrexone, opioid dependency, maintenance treatment program, treatment of opioid dependence, opioid maintenance treatment 


\title{
Availability of extended-release naltrexone may increase the number of opioid- dependent individuals in treatment. Extension of a randomized clinical trial
}

\begin{abstract}
Background and objective: Opioid maintenance treatment (OMT) is highly available in Norway, but only $50 \%$ of opioid-dependent individuals are enrolled in such programs. We aimed to examine if availability of extended-release naltrexone (XR-NTX) could attract individuals who for different reasons were not enrolled in an OMT program. Methods: In a Norwegian clinical study, $n=117$ opioid-dependent adults volunteered to receive XR-NTX in a 9-month period, as an extension of a previous randomized clinical trial. Results: Before study inclusion, $40.2 \%(n=47)$ of the study participants were not enrolled in OMT while the remainder were recruited from OMT. Participants not enrolled in OMT displayed more ongoing severe addiction-related problems such as heroin use $(p=0.002)$ but displayed a higher retention in treatment in the 9 -month extension study ( $p=0.048$ for log-rank test) than participants enrolled in OMT. Conclusion: Availability of XR-NTX attracted opioid-dependent individuals not previously enrolled in available OMT. While OMT may be perceived as a burden with regard to daily intake and control measures, one-monthly injections with XR-NTX may be perceived favourable offering more freedom to the patients, is being not addictive and reduces heroin craving. We suggest that an introduction of XR-NTX in Europe may increase the number of opioid-dependent individuals in treatment.
\end{abstract}

\section{Introduction}

It is of great importance to increase the overall number of opioid-dependent individuals in treatment, since treatment is the most crucial factor to prevent overdoses and reduce negative consequences of illicit opioid use for society $(1,2)$. The current recommended treatment option for opioid dependence is maintaining physical opioid dependence with opioid agonists like methadone or buprenorphine through opioid maintenance treatment 
programs (OMT) (3). OMT has shown well-documented improvements in illicit drug use, criminal behaviour and reduced risk of overdoses deaths (1, 4-9). A Norwegian study found that only $5-10 \%$ of the overdose deaths among opioid-dependent individuals occurred in patients enrolled in an OMT program, emphasizing the importance of such treatment programs (10). As for the majority of European countries, OMT in Norway is managed according to a low-threshold treatment guideline. However, despite its personal and societal advantages and the relatively free access to OMT in many European countries, it is estimated that only around $50 \%$ of opioid-dependent individuals in Europe receive such treatment (11).

Extended-release naltrexone (XR-NTX) is an alternative pharmacological treatment option for opioid dependence $(2,12)$. Naltrexone is an opioid antagonist that competitively blocks the effects of exogenous opioids (e.g., heroin) upon relapse and pharmacologically reduces cravings for opioids and alcohol (13-18). Naltrexone is considered as being a safe drug with few severe side-effects $(13,19-23)$. It lacks any potential for addiction and abuse (4), and prevents overdoses when used as described $(24,25)$. XR-NTX is administered as an intramuscular depot injection every fourth week, which may be perceived as favourable, compared to daily prescribed agonist treatment $(26,27)$. Two recently published randomized controlled trials (RCT) suggest that XR-NTX is as effective as buprenorphine-naloxone (BP$\mathrm{NLX})$ in retaining users in treatment and in reducing opioid use $(28,29)$. Both studies however, experienced dropouts from participants who failed to complete the mandatory detoxification period before naltrexone induction $(28,29)$.

XR-NTX is so far only approved in Russia and in the US, and most previous research has been conducted in these countries $(12,30)$. Since OMT is illegal in Russia but highly accessible in most Western European countries, the setting for the utilisation of XR-NTX is not comparable between Russia and Western Europe. Despite its demonstrated clinical effectiveness and broad insurance coverage, XR-NTX use in the United States has been limited, in part due to billing complexity and cost concerns (31). 
Two European user surveys have suggested that opioid-dependent individuals would welcome abstinence support with XR-NTX as a treatment option $(32,33)$, but such surveys are methodological limited to measuring attitudes rather than behaviour. Until recently, it has not been known how XR-NTX will be utilized in a clinical setting where OMT is easily available at no cost for the individual. Results from a Norwegian treatment study however, indicate that XR-NTX could be an alternative treatment option to a number of opioiddependent individuals in Europe $(28,34)$.

As in many other European countries, substance use disorder (SUD) treatment programs in Norway are a part of the national health care system and available at no cost to users. Very few patients are rejected when applying for the program. In 2015, $n=7498$ patients received treatment in OMT, estimated to be at least $50 \%$ of the Norwegian population of opioiddependent individuals (35).

The overall objective of this study was to examine if XR-NTX could have the potential to increase the number of opioid-dependent individuals in treatment. We conducted a secondary analysis of a previous reported follow-up study (34), and aimed to identify possible differences in baseline characteristics and retention rates among participants, based on their affiliation to OMT before study inclusion.

\section{Methods}

In the aforementioned follow-up study, $\mathrm{n}=117$ participants volunteered for treatment with XRNTX for a 9-month period (34). This was a subsequent follow-up to a previous published RCT (28).

\section{Design and setting}

The study was organized by The Norwegian Centre of Addiction Research (SERAF) and conducted in a naturalistic clinical setting at five urban hospitals in Norway from November 2012 to July 2015 (36). To be eligible, the opioid-dependent individuals must be willing to register in the national OMT program via one of the study hospitals after inclusion in the 
study but before study medication was administered. This guaranteed the participants' access to buprenorphine or methadone at no cost should they need so in the event of discontinuation from the study. Information about the study was given to opioid-dependent individuals at OMT clinics, detoxification units and other services. In a naturalistic manner, peer-based recommendations were permitted. At the time of this study XR-NTX was not registered for clinical use in Europe or Norway. XR-NTX was available only through the study, which was assumed to be the participants' primary motivation for volunteering for participation.

\section{Participants}

The participants in the 9-month follow-up study were recruited among those who were randomized in the RCT (28). In addition to the RCT completers, those who dropped-out during the RCT were offered re-inclusion in the 9-month follow-up (34). Participants were adults between 18 and 60 years old with opioid dependence disorder (DSM-IV). Before inclusion, all eligible patients underwent a general medical examination. Patients with serious somatic diseases, such as acute hepatic failure or an AIDS indicator disease were excluded from the study. Likewise, patients with serious chronic or acute mental disorders, such as psychosis or suicidality, were also non-eligible. Patients with less severe somatic or mental disorders were eligible for participation. Pregnant or breast-feeding women were excluded from participation, and female participants had to consent to use contraception during their participation in the study (36).

\section{Screening procedures}

Before inclusion in the RCT, all eligible patients were screened for serious mental disorders using the MINI 6.0 interview (37). They underwent interviews using the European version of the Addiction Severity Index (Europ-ASI) and completed several self-reporting questionnaires $(36,38)$. The Europ-ASI and the self-reporting questionnaires were also completed at the following study attendances every fourth week throughout the study period.

\section{Research ethics}


Opioid-dependent individuals who expressed interest in the study were given detailed information about the study, in particular about the possible effects and side effects of XRNTX. Information was provided both verbally and in writing, and participants were given a copy of their written informed consents. Participants were able to withdraw from the study at any time, and could commence substitution medication as part of OMT on the day of study discontinuation if medically feasible.

The study was approved by the Regional Committee for Medical and Health Research Ethics (\# 2011/1320), the Ethical Boards of the participating hospitals and the Norwegian Medicines Agency (EudraCT:2011-002858-31).

\section{Statistical analyses}

In this exploratory analysis of data from a previously published 9-month follow-up study, we included the participants based on affiliation to the OMT program prior to study. Categorical characteristics were presented as frequencies and percentages. Distribution of continuous characteristics was assessed by visual inspection of histograms. Symmetrically distributed variables were described by means and standard deviations (SD). Medians and minimum and maximum values were presented in addition to mean and SD for skewed variables. Differences between the study participants regarding their affiliation to the OMT program prior to inclusion were assessed by $\mathrm{X}^{2}$-test for categorical data and independent samples $\mathrm{t}$ test or quantile regression for continuous data when the variables of interest were skewed. Kaplan-Meier survival curves were plotted and log-rank test performed to assess the differences between OMT and not OMT groups in retention in treatment. All participants who took at least one dose of XR-NTX during the 9 months $(n=117)$ were included in the analyses.

Results with p-values below 0.05 were considered statistically significant. All tests were twosided. SPSS version 25 and SAS version 9.4 were used for the data analyses. 


\section{Results}

\section{Participant characteristics}

Participants characteristics in the 9-month follow-up study $(n=117)$ has previously been published (34). Before study enrolment, $n=47$ (40.2\%) of participants did not attend any OMT program. Table 1 provides a comparison of characteristics and addiction-related problems between participants enrolled in OMT and not enrolled in OMT before study inclusion.

\section{Table 1 about here>}

There were no statistically significant differences between the OMT and non-OMT groups in age at onset of heroin use, in duration of heroin use or in age at onset of injecting. Neither were there any significant differences between the groups in age at onset or in previous use of alcohol, cannabis or benzodiazepines.

Participants enrolled in OMT before study inclusion reported less current addiction-related problems, but showed higher scores on parameters associated with long-term addictionrelated health problems such as number of non-lethal overdoses (difference between medians of 2.0 (95\% Cl: $0.2 ; 3.8), p=0.032$ ), years of injecting drug use (difference between medians 3.0 ( $\mathrm{Cl}: 1.4 ; 7.4), \mathrm{p}=0.180)$, and being Hepatitis $\mathrm{C}$ sero-positive $(65.7 \%$ vs $31.9 \%$, $\mathrm{p}=0.002)$. As expected, OMT participants reported a higher consumption of substitution medication during the last 30 days before study enrolment (difference between medians 26.0 (Cl: 17.3; 30.0), $\mathrm{p}<0.001)$.

Conversely, participants not in OMT prior to study inclusion reported higher scores on parameters indicating more severe ongoing addiction-related problems in the last 30 days before study inclusion: More use of heroin (difference between medians -15.0 (Cl: -24.6; 5.4), $p=0.002$ ) and more money spent on illicit substances (difference between medians 6000 (Cl: -10103; -1897), $\mathrm{p}=0.004$ ) (table 1). Further, heroin was to a greater extent their major opioid addiction compared to those enrolled in OMT (76.1\%, respectively $53.8 \%)$.

\section{Retention in treatment}


At the start of the 9-month follow-up, 59.8\% $(n=70)$ of the participants were enrolled in OMT and $40.2 \%(n=47)$ were not prior to study inclusion.

At the end of the 9-month follow-up, $50 \%(n=29)$ of the $n=58$ completers came from OMT and $50 \%(n=29)$ did not prior to study inclusion. The non-OMT group displayed significantly longer retention in treatment compared to the OMT group (mean weeks $28.3(\mathrm{Cl} 25.2 ; 31.4)$ vs 23.7 (Cl 20.9; 26.6), p=0.048 for log-rank test) (figure1).

\section{$<$ Figure 1 about here>}

\section{Discussion}

Offering extended-release naltrexone (XR-NTX) for the first time in Norway and in Western Europe attracted a representative sample of opioid-dependent individuals. The participants' characteristics were within the range of variability previously documented in other studies of opioid-dependent individuals $(19,35,39,40)$.

Our study showed that XR-NTX seemed to attract a proportion of opioid-dependent individuals who appear to have been unwilling to receive OMT. These participants $(40.2 \%)$ reported more severe ongoing addiction-related problems compared to the participants recruited from the OMT-population, and were at higher risk of overdose due to their pattern of uncontrolled use of illicit substances (35). In a previous survey performed by our research group, opioid-dependent individuals not currently in OMT reported a higher interest in XRNTX treatment than those enrolled in OMT (32). Thus, a number of opioid-dependent individuals whom for different reasons have chosen not to be enrolled in an available OMT treatment, have shown, both in attitude and in behaviour, attraction to XR-NTX treatment. Furthermore, these participants maintained significantly longer in XR-NTX treatment, compared to those enrolled in OMT prior to study inclusion. This is an encouraging finding suggesting that a substantial numbers of these individuals could benefit from XR-NTX 
treatment, and furthermore entail an increase in number of opioid-dependent individuals in treatment.

Existing OMT patients comprised the majority of XR-NTX volunteers $(59.8 \%)$ who by volunteering for medication-assisted abstinence with XR-NTX took action towards discontinuing their daily agonist maintenance medication (usually buprenorphine). These OMT participants reported a more severe history of addiction-related health problems, but in line with previous studies, both health and psychosocial factors improved while these participants were in OMT $(4,5)$. However, OMT enrolment do also carry a burden for individuals, such as daily monitored intake of opioids and frequent urine drug testing, and a perception of stigma and a manifestation of an addictive identity (26, 27, 41, 42). Although OMT being an effective treatment alternative, studies have shown that intravenous misuse of OMT-medication and illicit substances is not uncommon among OMT-populations (43). In contrast, studies of XR-NTX treatment have reported rather low rates of opioid use, reduced heroin craving, a high degree of treatment satisfaction and increased life satisfaction, suggesting XR-NTX as a potential effective treatment option (28, 29, 34).

Previous studies have reported that many patients in OMT express a main goal of opioid abstinence $(33,44,45)$. The before mentioned survey conducted by our research team, also discovered a high interest in XR-NTX treatment among OMT-patients (32). Since discontinuing substitution medication is risky even when patients are highly motivated, rather few succeed in detoxification from OMT and many relapse to opioid use (46). This implies that opioid-dependent individuals are recommended to stay in OMT, maintaining their opioid dependence and thus, the rate of opioid-free patients remains low (9). Treatment with XRNTX may offer a safer medication-assisted abstinence and be perceived by the patients as a strong support in a transition phase towards medication-free abstinence. XR-NTX treatment provides an opioid-free alternative, which may considerably change the current treatment scope. 
The difference in retention between those enrolled in and those not enrolled in OMT prior to study inclusion, may reflect their experience - or lack of experience - with OMT. Concerning the participants not enrolled in OMT prior to study inclusion, we suggest that the motivation for staying in XR-NTX treatment corresponded with the motivation for not enrolling into OMT. The administration of naltrexone implies fewer of the inconveniences of daily living that opioid-dependent individuals experience as hindrances for enrolment in OMT $(26,27,42)$. On the contrary, participants previous enrolled in OMT who experienced improvements in various addiction-related problems during this treatment may more easily return to OMTtreatment if they disliked any effects of XR-NTX. The study personnel also experienced that a number of OMT participants were satisfied with a shorter period of time in treatment, and ended their XR-NTX treatment before the pre-scheduled time. These participants had received treatment for opioid dependence for a longer period, were typically already recovered due to a successful OMT program before study inclusion, and wanted XR-NTX in a shorter transition phase towards a main goal of medication-free abstinence.

Patients with severe ongoing addiction-related problems can be "hard to reach" and have limited contact with specialized health services (47). OMT has been shown to be effective in such "hard to reach" patients in low-threshold setting with regard to harm reduction purposes (47). Based on our clinical experience from the present study, treatment with XR-NTX could also be relevant for harm reduction purposes in this group of patients. One hindrance however, is that XR-NTX requires a complete detoxification from opioids before the first injection of XR-NTX can be administered. This procedure may prevent patients to be inducted to XR-NTX (29). If induction to XR-NTX is successful however, these patients might adhere more easily to a medication that is administered once every 4 weeks instead of once daily (28). Further studies are needed to investigate to which degree XR-NTX could be effective for harm reduction purposes in this population of patients.

Our results should be understood as hypothesis-generating for future naturalistic studies that could confirm the results of the present study. Previous studies have not discriminated 
between different lengths of treatment concerning the opioid-dependent individuals'

motivation for XR-NTX treatment. As for other treatment programs, XR-NTX treatment should be adapted according to the individual preferences and needs. This is important knowledge for clinicians and future studies of XR-NTX should also address this issue.

\section{Conclusions}

Opioid-dependent individuals not currently enrolled in OMT were attracted to this novel treatment modality and adhered longer to XR-NTX treatment than those enrolled in OMT prior to study inclusion. Adherence to XR-NTX treatment may be better among those who prefer not to enrol in OMT due to individual reasons such as less frequent dosing and/or less stigma of antagonist treatment. The prospects for patients in regaining opioid-abstinence with XR-NTX are very different from the current applied treatment in OMT, and induction to XRNTX may result in a paradigm shift regarding treatment of opioid-dependent individuals. We suggest that XR-NTX has the potential to increase the overall number of opioid-dependent individuals in treatment, and that XR-NTX should be an available treatment option to opioiddependent individuals in Europe.

\section{References}

1. Degenhardt L, Bucello C, Mathers B, Briegleb C, Ali H, Hickman M, et al. Mortality among regular or dependent users of heroin and other opioids: a systematic review and meta-analysis of cohort studies. Addiction. 2011;106(1):32-51.

2. Volkow ND, Frieden TR, Hyde PS, Cha SS. Medication-assisted therapies--tackling the opioidoverdose epidemic. The New England journal of medicine. 2014;370(22):2063-6.

3. WHO. Guidelines for the Psychosocially Assisted Pharmacological Treatment of Opioid Denpendence. http://www.who.int/substance abuse/activities/treatment opioid dependence/en/: World Health Organization; 2009.

4. Connery HS. Medication-assisted treatment of opioid use disorder: review of the evidence and future directions. Harvard review of psychiatry. 2015;23(2):63-75.

5. Mattick RP, Breen C, Kimber J, Davoli M. Buprenorphine maintenance versus placebo or methadone maintenance for opioid dependence. Cochrane Database of Systematic Reviews. 2014;2. 6. Clausen T, Anchersen K, Waal H. Mortality prior to, during and after opioid maintenance treatment (OMT): a national prospective cross-registry study. Drug and alcohol dependence. 2008;94(1-3):151-7. 
7. Bukten A, Roislien J, Skurtveit S, Waal H, Gossop M, Clausen T. A day-by-day investigation of changes in criminal convictions before and after entering and leaving opioid maintenance treatment: a national cohort study. BMC Psychiatry. 2013;13:262.

8. Bart G. Maintenance medication for opiate addiction: the foundation of recovery. Journal of addictive diseases. 2012;31(3):207-25.

9. Soyka M, Strehle J, Rehm J, Buhringer G, Wittchen HU. Six-Year Outcome of Opioid Maintenance Treatment in Heroin-Dependent Patients: Results from a Naturalistic Study in a Nationally Representative Sample. European addiction research. 2017;23(2):97-105.

10. Waal H, Bussesund K, Clausen T, Skeie I, Håseth A, Lillevold P. The annual OMT status survey for 2014 (In Norwegian only: Statusrapport 2014-En aldrende LAR-populasjon). Norwegian Centre for Addiction Research; 2015.

11. EMCDDA. European Drug Report: Trend and Developments.

http://www.emcdda.europa.eu/publications/edr/trends-developments/2015: European Monitoring Centre for Drugs and Drug Addiction; 2015.

12. Gastfriend DR. A pharmaceutical industry perspective on the economics of treatments for alcohol and opioid use disorders. Annals of the New York Academy of Sciences. 2014;1327:112-30.

13. Krupitsky E, Nunes EV, Ling W, Gastfriend DR, Memisoglu A, Silverman BL. Injectable extended-release naltrexone (XR-NTX) for opioid dependence: long-term safety and effectiveness. Addiction. 2013;108(9):1628-37.

14. Sideroff $S$, Charuvastra V, Jarvik M. Craving in heroin addicts maintained on the opiate antagonist naltrexone. The American journal of drug and alcohol abuse. 1978;5.

15. Sullivan MA, Bisaga A, Mariani JJ, Glass A, Levin FR, Comer SD, et al. Naltrexone treatment for opioid dependence: does its effectiveness depend on testing the blockade? Drug and alcohol dependence. 2013;133(1):80-5.

16. Herbeck DM, Jeter KE, Cousins SJ, Abdelmaksoud R, Crèvecoeur-MacPhail D. Gender differences in treatment and clinical characteristics among patients receiving extended release naltrexone. Journal of addictive diseases. 2016;35(4):305-14.

17. Martin WR, Jasinski DR, Mansky PA. Naltrexone, an antagonist for the treatment of heroin dependence. Effects in man. Archives of general psychiatry. 1973;28(6):784-91.

18. Chiang CN, Hollister LE, Gillespie HK, Foltz RL. Clinical evaluation of a naltrexone sustainedrelease preparation. Drug and alcohol dependence. 1985;16(1):1-8.

19. Kunøe N, Lobmaier P, Vederhus JK, Hjerkinn B, Hegstad S, Gossop M, et al. Naltrexone implants after in-patient treatment for opioid dependence: randomised controlled trial. The British journal of psychiatry. 2009;194(6):541-6.

20. Garbutt JC, Kranzler HR, O'Malley SS, Gastfriend DR, Pettinati HM, Silverman BI, et al. Efficacy and tolerability of long-acting injectable naltrexone for alcohol dependence: a randomized controlled trial. . JAMA. 2005;293:1617-25.

21. Gastfriend DR. Intramuscular extended-release naltrexone: current evidence. Annals of the New York Academy of Sciences. 2011;1216:144-66.

22. Comer SD, Sullivan MA, Yu E, Rothenberg JL, Kleber HD, Kampman K, et al. Injectable, sustained-release naltrexone for the treatment of opioid dependence: a randomized, placebocontrolled trial. Archives of general psychiatry. 2006;63(2):210-8.

23. Hulse GK, Morris N, Arnold-Reed D, Tait RJ. Improving clinical outcomes in treating heroin dependence: randomized, controlled trial of oral or implant naltrexone. Archives of general psychiatry. 2009;66(10):1108-15.

24. Digiusto E, Shakeshaft A, Ritter A, O'Brien S, Mattick RP. Serious adverse events in the Australian National Evaluation of Pharmacotherapies for Opioid Dependence (NEPOD). Addiction. 2004;99(4):450-60.

25. Kunøe N, Lobmaier P, Ngo HT, Hulse G. Injectable and implantable sustained release naltrexone in the treatment of opioid addiction. British Journal of Clinical Pharmacology.

2014;77(2):264-71. 
26. Vanderplasschen W, Naert J, Vander Laenen F, De Maeyer J. Treatment satisfaction and quality of support in outpatient substitution treatment: opiate users' experiences and perspectives. Drugs: Education, Prevention and Policy. 2015;22(3):272-80.

27. Harris J, McElrath K. Methadone as social control: institutionalized stigma and the prospect of recovery. Qualitative health research. 2012;22(6):810-24.

28. Tanum L, Solli KK, Latif ZE, Benth JS, Opheim A, Sharma-Haase K, et al. Effectiveness of Injectable Extended-Release Naltrexone vs Daily Buprenorphine-Naloxone for Opioid Dependence: A Randomized Clinical Noninferiority Trial. JAMA Psychiatry. 2017;74(12):1197-205.

29. Lee JD, Nunes EV, Jr., Novo P, Bachrach K, Bailey GL, Bhatt S, et al. Comparative effectiveness of extended-release naltrexone versus buprenorphine-naloxone for opioid relapse prevention (X:BOT): a multicentre, open-label, randomised controlled trial. Lancet. 2018;391(10118):309-18.

30. Krupitsky E, Nunes EV, Ling W, Illeperuma A, Gastfriend DR, Silverman BL. Injectable extended-release naltrexone for opioid dependence: a double-blind, placebo-controlled, multicentre randomised trial. Lancet. 2011;377(9776):1506-13.

31. Aletraris L, Edmond MB, Roman PM. Adoption of injectable naltrexone in US substance use disorder treatment programs. Journal of studies on alcohol and drugs. 2015;76(1):143-51.

32. Sharma Haase K, Kunoe N, Opheim A, Gaulen Z, Nja AM, Latif ZE, et al. Interest in Extended Release Naltrexone among Opioid Users. European addiction research. 2016;22(6):301-5.

33. Zaaijer ER, Goudriaan AE, Koeter MW, Booij J, van den Brink W. Acceptability of ExtendedRelease Naltrexone by Heroin-Dependent Patients and Addiction Treatment Providers in the Netherlands. Substance Use and Misuse. 2016;51(14):1905-11.

34. Solli KK, Latif ZE, Opheim A, Krajci P, Sharma Haase K, Tanum L, et al. Effectiveness, safety and feasibility of extended-release naltrexone for opioid dependence: a nine-month follow-up to a three-month randomized trial. Addiction 2018;113(10):1840-9.

35. Waal H, Bussesund K, Clausen T, Skeie I, Håseth A, Lillevold P. The annual OMT status survey for 2015 (In Norwegian only: Statusrapport 2015-Mot grensene for vekst og nytte?). Norwegian Centre for Addiction Research; 2016.

36. Kunøe N, Opheim A, Solli KK, Gaulen Z, Sharma-Haase K, Latif ZE, et al. Design of a randomized controlled trial of extended-release naltrexone versus daily buprenorphine-naloxone for opioid dependence in Norway (NTX-SBX). BMC Pharmacology and Toxicology. 2016;17(1):1-10.

37. Sheehan DV, Lecrubier Y, Sheehan KH, Amorim P, Janavs J, Weiller E, et al. The MiniInternational Neuropsychiatric Interview (M.I.N.I.): the development and validation of a structured diagnostic psychiatric interview for DSM-IV and ICD-10. The Journal of clinical psychiatry. 1998;59 Suppl 20.

38. Kokkevi A, Hartgers C. EuropASI: European Adaptation of a Multidimensional Assessment Instrument for Drug and Alcohol Dependence. European addiction research. 1995;1(4):208-10.

39. Indergård PJ, Solbakken T, Urfjell B. Activity data for mental health services for adults and specialized substance abuse treatment 2014 (In Norwegian only: Aktivitetsdata for psykisk helsevern for voksne og tverrfaglig spesialisert rusbehandling 2014). 2014.

40. Cousins SJ, Radfar SR, Crevecoeur-MacPhail D, Ang A, Darfler K, Rawson RA. Predictors of Continued Use of Extended-Released Naltrexone (XR-NTX) for Opioid-Dependence: An Analysis of Heroin and Non-Heroin Opioid Users in Los Angeles County. Journal of Substance Abuse Treatment. 2016;63:66-71.

41. Larney S, Zador D, Sindicich N, Dolan K. A qualitative study of reasons for seeking and ceasing opioid substitution treatment in prisons in New South Wales, Australia. Drug and alcohol review. 2016;36(3):305-10.

42. Deering DE, Sheridan J, Sellman JD, Adamson SJ, Pooley S, Robertson R, et al. Consumer and treatment provider perspectives on reducing barriers to opioid substitution treatment and improving treatment attractiveness. Addictive Behaviours. 2011;36(6):636-42.

43. Lugoboni F, Zamboni L, Cibin M, Tamburin S. Intravenous Misuse of Methadone, Buprenorphine and Buprenorphine-Naloxone in Patients Under Opioid Maintenance Treatment: A Cross-Sectional Multicentre Study. European addiction research. 2019;25(1):10-9. 
44. Neale J, Nettleton S, Pickering L. What is the role of harm reduction when drug users say they want abstinence? International Journal of Drug Policy. 2011;22(3):189-93.

45. Notley C, Blyth A, Maskrey V, Craig J, Holland R. The experience of long-term opiate maintenance treatment and reported barriers to recovery: a qualitative systematic review. European addiction research. 2013;19(6):287-98.

46. Magura S, Rosenblum A. Leaving methadone treatment: lessons learned, lessons forgotten, lessons ignored. The Mount Sinai journal of medicine. 2001;68(1):62-74.

47. Henriksen K, Jacobsen JA, Henriksen EM, Gomes L, Waal H, Krajci P. The LASSO Program in Oslo: Harm Reduction Using Buprenorphine-Naloxone (Suboxone(R)) in a Low Threshold Setting. European addiction research. 2018;24(6):286-92. 
Table 1 Differences within the study group

\begin{tabular}{|c|c|c|c|c|}
\hline & $\begin{array}{c}\text { In OMT } \\
\mathrm{n}=70(59.8 \%)\end{array}$ & $\begin{array}{c}\text { Not in OMT } \\
n=47 \\
(40.2 \%)\end{array}$ & $\begin{array}{l}\text { Difference } \\
\text { between } \\
\text { medians } \\
(95 \% \mathrm{Cl})\end{array}$ & p-value \\
\hline Gender & & & & $0.060^{2}$ \\
\hline Male & $49(70.0)$ & $40(85.1)$ & & \\
\hline Female & $21(30.0)$ & $7(14.9)$ & & \\
\hline Age & $36.2(7.9)$ & $34.6(9.1)$ & & $0.309^{4}$ \\
\hline \multicolumn{5}{|l|}{$\begin{array}{l}\text { Substitution medication, } \\
\text { days of use last } 30 \text { days } \\
\mathrm{N}\end{array}$} \\
\hline Mean (SD) & $18.0(13.5)$ & $7.9(10.8)$ & & \\
\hline Median (min-max) & $28(0-30)$ & $2(0-30)$ & 26.0 & $<0.001^{1}$ \\
\hline \multicolumn{5}{|l|}{$\begin{array}{l}\text { Heroin, days of use last } \\
30 \text { days }\end{array}$} \\
\hline $\mathrm{N}$ & 67 & 46 & & \\
\hline Mean (SD) & $7(10.7)$ & $14.5(12.4)$ & & \\
\hline Median (min-max) & $0(0-30)$ & $15(0-30)$ & $\begin{array}{c}-15.0 \\
(-24.6 ;-5.4)\end{array}$ & $0.002^{1}$ \\
\hline \multicolumn{5}{|l|}{ Years with injection use } \\
\hline $\mathrm{N}$ & 66 & 45 & & \\
\hline Mean (SD) & $11.0(8.8)$ & $8.5(9.3)$ & & \\
\hline Median (min-max) & $8(0-40)$ & $5(0-35)$ & $3.0(-1.4 ; 7.4)$ & $0.180^{1}$ \\
\hline Hepatitis C sero-positive & & & & $<0.002^{2}$ \\
\hline Don't know, N (\%) & $1(1.4)$ & $2(4.3)$ & & \\
\hline No, N (\%) & $23(32.9)$ & $30(63.8)$ & & \\
\hline Yes, N (\%) & $46(65.7)$ & $15(31.9)$ & & \\
\hline \multicolumn{5}{|l|}{ Overdoses lifetime } \\
\hline $\mathrm{N}$ & 68 & 46 & & \\
\hline Mean (SD) & $6(8.6)$ & $2.6(3.9)$ & & \\
\hline Median (min-max) & $3.0(0-50)$ & $1.0(0-15)$ & $2.0(0.2 ; 3.8)$ & $0.032^{1}$ \\
\hline \multicolumn{5}{|l|}{$\begin{array}{l}\text { Acquisitive crime last } 30 \\
\text { days }\end{array}$} \\
\hline $\mathrm{N}$ & 69 & 45 & & \\
\hline Mean (SD) & $4.9(9.9)$ & $8.0(11.6)$ & & \\
\hline Median (min-max) & $0(0-30)$ & $0(0-30)$ & & $\mathrm{NA}^{3}$ \\
\hline \multicolumn{5}{|l|}{$\begin{array}{l}\text { Money spent on illlicit } \\
\text { substances last } 30 \text { days } \\
\text { (NOK) }\end{array}$} \\
\hline $\mathrm{N}$ & 69 & 46 & & \\
\hline Mean (SD) & $6746(12220)$ & $\begin{array}{c}13139 \\
(158909)\end{array}$ & & \\
\hline Median (min-max) & $\begin{array}{l}2000(0- \\
75000)\end{array}$ & $\begin{array}{l}8000(0- \\
75000)\end{array}$ & $\begin{array}{c}-6000(- \\
10103 ;-1897)\end{array}$ & $0.004^{1}$ \\
\hline
\end{tabular}




\section{Figure 1 Survival curve for retention in treatment}

Survival curve for retention in treatment, based on participants affiliation to OMT. The curve display retention in the 9-month follow-up.

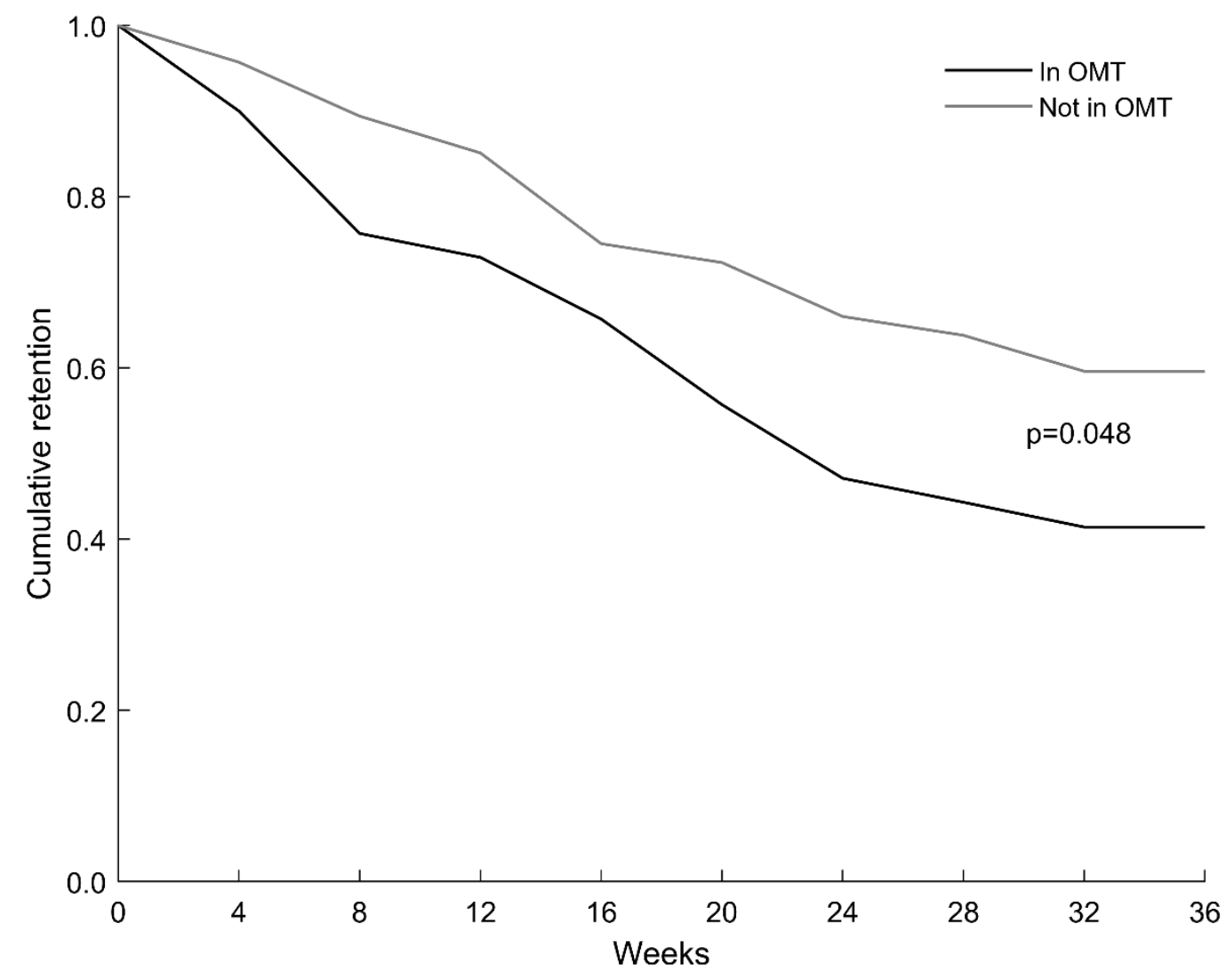

